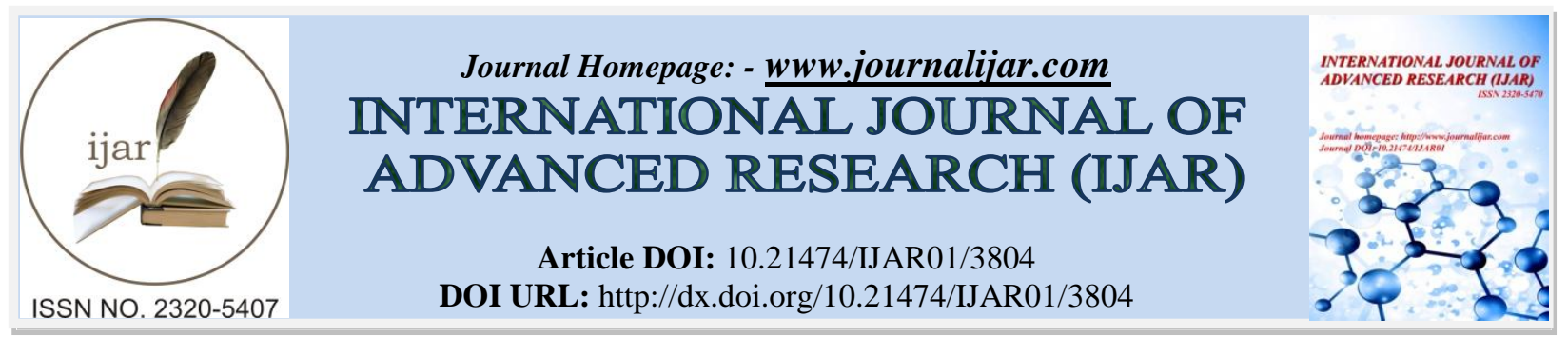

RESEARCH ARTICLE

\title{
UNUSUAL PRESENTATION OF SUPRACARDIAC TAPVD IN 5 YEARS OLD BOY.
}

\section{Dr. Abdulrahman Bakhaider ${ }^{1}$, Dr. Roa'a AlFarshooti ${ }^{2}$, Dr.Ruba Al-manzalawi ${ }^{2}$, Dr.Attia Alshaikh ${ }^{3}$, Dr.} Nojood Al-Harbi ${ }^{4}$ and Dr.Abdullah Al-Qahtani ${ }^{5}$.

1. Chief of pediatric cardiology division, consultant pediatric cardiology, maternity \& children hospital Jeddah, Saudi Arabia

2. Pediatric resident, maternity \& children hospital Jeddah, Saudi Arabia,

3. Consultant pediatric emergency, maternity \& children hospital Jeddah, Saudi Arabia

4. Pediatric resident, King Fahd Armed Forces Hospital Jeddah, Saudi Arabia,

5. Consultant pediatric cardiology, maternity \& children hospital Jeddah, Saudi Arabia.

\section{Manuscript Info}

Manuscript History

Received: 01 February 2017

Final Accepted: 11 March 2017

Published: April 2017

\begin{abstract}
Unusual presentation for 5 years old boy who come to general pediatric clinic complaining of failure to thrive and mild cyanosis, referred to pediatric cardiology to ruled out congenital cardiac disease, as an ejection systolic murmur heard in the left upper sternal border plus the mild cyanosis, oxygen saturation by pulse oximitry is $88 \%$ in room air.
\end{abstract}

Copy Right, IJAR, 2017,. All rights reserved.

\section{Background:-}

Total anomalous pulmonary venous drainage (TAPVD) is rare, comprising of approximately $1.5 \%$ of all congenital heart abnormalities. It is usually diagnosed in the neonatal period and is rarely seen in children or adults. It requires surgical correction for survival as no catheter corrective treatment exists. In patients with TAPVD, all the venous blood returning from the lungs drains to the systemic veins, creating a large left-to-right shunt. Supply of oxygenated blood to the systemic circulation requires an atrial septal defect to allow oxygenated blood to enter the left ventricle. Without surgery, $80 \%$ babies with TAPVD die before their first birthday. We report a case of 5-yearold boy who diagnosed as supracardiac TAPVD.

\section{Case Report:-}

Unusual presentation for 5 years old boy who come to general pediatric clinic complaining of failure to thrive and mild cyanosis, referred to pediatric cardiology to ruled out congenital cardiac disease, as an ejection systolic murmur heard in the left upper sternal border plus the mild cyanosis, oxygen saturation by pulse oximitry is $88 \%$ in room air. Other ways he is normal physically and mentally.

On examination his vital sings within normal apart from oxygen saturation, which was $86-88 \%$ in room air. His weight was $13 \mathrm{~kg}$, which below the $5^{\text {th }}$ percentile for his age and gender. Mild clubbing, Quite pericardium and normal first and loud second heart sounds. An ejection systolic murmur greed 2/6 heard on LUSB.

\section{Investigations:-}

$\mathrm{CBC}$ and Chemistry are both within normal range.

CXR showed mild cardiomegaly with congested lungs and clear snowman appearance. 
Echocardiography showed supracardiac type of TAPVD, All pulmonary veins drainage to common pulmonary connection which drainage to vertical vein with mild stenosis, which finally drained to SVC than to RA.

Mild restriction at the intra-arterial shunt, with R-L shunt.

Moderate RA/RV dilatation

Catheterization done and confirmed the diagnosis of echocardiography.

Patient was referred to cardiac center where cardiac surgery done with excellent outcome, he was seen on regular visits to cardiac clinic with no complications till this moment almost two years post-operative .

\section{Comment:-}

The TAPVD results from failure of primordial pulmonary vein to unite with the lung plexus of the veins. Therefore, the pulmonary veins drain to the heart through systemic veins to the right atrium. In TAPVD, supply of oxygenated blood to the systemic circulation requires intracardiac communication between the right and left sides of the heart to allow oxygenated blood to enter the left ventricle. The size of the communication determines the volume of blood able to cross to the left heart, and therefore it determines the cardiac output and systemic oxygenation. In supracardiac TAPVD, the ascending vein usually unites with the innominate vein, which may drain directly to the superior vena cava or the azygous vein. In the infracardiac TAPVD, a descending vein drains either to the inferior vena cava, the portal vein, hepatic veins, or ductus venosus.

In cardiac TAPVD, the anomalous veins drain into the coronary sinus or directly to the right atrium.

Patients with TAPVD usually present in the early neonatal period, often with profound cyanosis and shock, and they almost always require surgical treatment in the neonatal period, often on an emergency basis.

There are two anatomic factors that determine the patient's clinical status. First, the patient's cardiac output and supply of oxygenated blood is limited by the amount of blood that can cross the atrial septum. Therefore, the characteristics of the necessary right-to-left shunt determine systemic cardiac output and oxygenation. Second, an obstruction may occur in the path of the pulmonary venous drainage from the lungs to the systemic venous system. If obstruction occurs, egress of blood from the lungs is limited. The consequences of obstruction are limitation of pulmonary blood flow, pulmonary venous congestion, impairment of oxygenation, and elevation of pulmonary artery pressures. These events lead to life-threatening cyanosis in neonates. Increased pulmonary blood flow and pulmonary venous obstruction will result in pulmonary hypertension and eventually heart failure.

Survival until the age of 5 is unusual, and increasing age is described as an unfavorable factor for successful surgical outcome. In this particular patient, survival to this age can be attributed to supracardiac type of TAPVD, an unobstructed pulmonary venous flow, a large intracardiac shunt to maintain the cardiac output, and a normalized left ventricle. Moreover, there were neither any associated anomalies nor any preoperative acidosis. Post repair, there was no residual obstruction at the site of left atrial anastomosis, which could manifest as poor cardiac output and chest roentgenogram findings of pulmonary congestion. Approximately $10 \%$ to $15 \%$ of patients have evidence of late pulmonary vein obstruction, which tends to be recurrent and progressive. For this reason, long-term surveillance is important.

In conclusion, this report describes a case of unusual presentation of 5 years old with mild obstructed supracardiac TAPVD in a 5-year-old boy who was present late to the medical attention complaining of mild cyanosis and FTT and finally he was successfully treated by surgery. However, careful perioperative assessment of this small group of patients is needed to exclude the presence of anatomical and physiological factors that could affect the outcome adversely. For surgery to be successful, a clear management plan should be drawn up for the preoperative, operative, and postoperative management of such patients in consultation with pediatric cardiologists, cardiac surgeons, anesthetists, and intensivists. Despite an excellent early outcome, late outcome is unknown.

\section{Acknowledgment:-}

We thank his parents who agreed to publish this case for educational purposes. 


\section{References:-}

1. Franceschini P, Guala A, Licata D, Di Cara G, Franceschini D. Arterial tortuosity sindrome. Am J Med Genet 2000;91:141-3.

2. Zaidi SHE, Peltekova V, Meyer S, et al. A family exhibiting arterial tortuosity syndrome displays homozygosity for markers in the arterial tortuosity locus at chromosome 20q13. Clin Genet 2004;67:183-8.

3. Hoop R, Steinmann B, Valsangiacomo Buechel ER, Cardiovascular findings in arterial tortuosity syndrome. Eur Heart J 2006;27:2045.

4. Bottio T, Bisleri G, Piccoli P, Muneretto C. Valve-sparing aortic root replacement in a patient with a rare connective tissue disorder: arterial tortuosity syndrome. J Thorac Cardiovasc Surg 2007;133:252-3.

5. Rivera IR, Gomes L, Moises VA, Silva CC, Andrade JL, Carvalho AC. Multiple arterial anomalies in the newborn infant. Echocardiographic and angiographic diagnosis. Arq Bras Cardiol 2000;75:141- 4.

6. Coucke PJ, Willaert A, Wessels MW, et al. Mutations in the facilitative glucose transported GLUT10 alter angiogenesis and cause arterial tortuosity sindrome. Nat Genet 2006;38: 452-7.

7. Ferencz C, Rubin JD, Loffredo CA, Magee CM. The epidemiology of congenital heart disease, the BaltimoreWashington infant study (1981-1989). Perspectives in pediatric cardiology, Vol 4. Mount Kisco, NY: Futura Publishing Co Inc; 1993.

8. Correa-Villasenor A, Ferencz C, Boughman JA, Neill CA. Total anomalous pulmonary venous return: familial and environmental factors. The Baltimore-Washington Infant Study Group. Teratology 1991;44:415-28.

9. Gathman GE, Nadas AS. Total anomalous pulmonary venous connection: clinical and physiologic observations of 75 pediatric patients. Circulation 1970;42:143-54.

10. Behrendt DM, Aberdeen E, Waterson DJ, Bonham-Carter RE. Total anomalous pulmonary venous drainage in infants. I. Clinical and hemodynamic findings, methods, and results of operation in 37 cases. Circulation 1972;46:347-56.

11. Sano S, Brawn WJ, Mee RB. Total anomalous pulmonary venous drainage. J Thorac Cardiovasc Surg 1989;97: $886-92$.

12. Yalta K, Turgut OO, Yilmaz A. Asymptomatic total anomalous pulmonary venous connection with double drainage in a young adult: a case report. Heart Surg Forum 1007;10: E211-2. 